\title{
Targeting Breast Cancer Associated Gene 2 (bca2), a Novel Ubiquitin e3 Ligase for Breast Cancer Treatment
}

\section{Fathima Rani Kona and Q Ping Dou*}

Barbara Ann Karmanos Cancer Institute, Departments of Oncology, Pharmacology and Pathology, School of Medicine, Wayne State University, USA

Breast cancer is the second leading cause of cancer-related death in women, comprising about $23 \%$ of all cancers diagnosed worldwide [1]. A common phenotype in breast cancer is the abnormal expression of Estrogen Receptor- $\alpha$ (ER) and it has been well documented that estrogens and Estrogen Receptors (ERs) play essential roles in breast cancer development and progression [2]. ER functions as the major regulator of phenotypic properties in estrogen-responsive tumors by controlling transcription of different genes thereby influencing cell proliferation.

Breast Cancer Associated Gene 2 (synonymous with ZNF364/ Rabring 7/ RNF115) is a RING-finger ubiquitin E3 ligase, which was identified by the subtractive hybridization cloning method and was shown to be associated with ER-positive status in human breast tumors [3]. BCA2 was found to be over-expressed in primary invasive breast cancers and initially predicted to be correlated with negative lymph node metastasis and increased survival [3]. Inhibition of BCA2 by its siRNA in MCF7 and T47D cell lines decreased cell proliferative capacity, indicating that it plays an important role in cell migration [3]. A more recent study using high resolution genome-wide chromosomal alteration analysis revealed a high copy number of BCA2 in Burkitt's lymphoma [4]. BCA2 was also found to bind to UBC9, suggesting its involvement in sumoylation pathway [5]. Because of its known RING E3 ligase activity, BCA2 is capable of regulating its own stability by undergoing autoubiquitination [6]. By binding to hHR23a and 14-3-3, which stabilizes BCA2, BCA2 is proposed to play an important role in breast cancer progression [7]. BCA2 is also a target protein in vesicle traffic to late endosome/lysosome in lysosome biogenesis and is also proposed to interact with ALG2 [8]. On a positive front, BCA2 has been found to play an important role as a host cell factor by accelerating the internalization and degradation of HIV viral particles following their tethering to the cell surface in infected cells [9]. This diverse biology of BCA2 suggests that it has multiple cellular functions.

Although, BCA2 promoter contains several Estrogen-ResponseElement (ERE) half-sites, the role of ER in the regulation of BCA2 transcription has not been elucidated. We have recently reported that the transcriptional regulation of BCA2 in ER-positive breast cancer cell lines is controlled by ER and that BCA2 gene expression is regulated by an estradiol-dependent mechanism in these breast cancer cells [10]. This extends our previous work about co-expression of BCA2 gene with the ER in $74 \%$ of ER-positive invasive ductal carcinomas in a breast cancer cohort of 635 patients and regulation of BCA 2 mRNA by estrogen [5]. This finding suggests that BCA2 is potentially involved in hormone-responsive breast cancer and understanding its regulation by ER is important to exploit its importance in breast cancer progression and treatment.

The Ubiquitin-Proteasome System (UP-S) plays a central role in protein homeostasis and has been implicated in the pathogenesis of several human diseases including cancer. UP-S has been well documented as a novel target for anticancer therapies [11]. Protein ubiquitination and degradation is tightly regulated by the UP-S and the
E3 ligases provide substrate specificity to this system. Many E3 ligases are either oncogene products or tumor suppressors and are shown to be deregulated in carcinogenesis. Some E3 ligases, like MDM2 and SCF complex, play a major role in the cell cycle and apoptosis [12]. Other tumor suppressor E3 ligases include BRCA1, CHIP and CUL-5 [13].

Although more than 500 E3 ligases have been identified, their targets are yet to be discovered. We hypothesize that E3 ligases like BCA2 that are overexpressed in many cancer types with unknown target substrates play a major role in carcinogenesis. We believe that understanding the regulation and mechanisms of action of BCA2 and other E3 ligases and identification of their substrates is critical for designing and developing specific targeted anticancer therapies.

\section{References}

1. Jemal A, Siegel R, Xu J, Ward E (2010) Cancer statistics, 2010. CA Cancer J Clin 60: 277-300.

2. Oh DS, Troester MA, Usary J, Hu Z, He X, et al. (2006) Estrogen-regulated genes predict survival in hormone receptor-positive breast cancers. $J$ Clin Oncol 24: 1656-1664.

3. Burger AM, Gao Y, Amemiya Y, Kahn HJ, Kitching R, et al. (2005) A novel RING-type ubiquitin ligase breast cancer-associated gene 2 correlates with outcome in invasive breast cancer. Cancer Res 65: 10401-10412.

4. Toujani S, Dessen P, Ithzar N, Danglot G, Richon C, et al. (2009) High resolution genome-wide analysis of chromosomal alterations in Burkitt's lymphoma. PLoS One 4: e7089.

5. Burger AM, Kona F, Amemiya Y, Gao Y, Bacopulos S, et al. (2010) Role of the BCA2 ubiquitin E3 ligase in hormone responsive breast cancer. Open Cancer J 3: 116-123.

6. Amemiya $Y$, Azmi P, Seth A (2008) Autoubiquitination of BCA2 RING E3 ligase regulates its own stability and affects cell migration. Mol Cancer Res 6: 13851396.

7. Bacopulos S, Amemiya Y, Yang W, Zubovits J, Burger A, et al. (2012) Effects of partner proteins on BCA2 RING ligase activity. BMC Cancer 12: 63

8. Mizuno K, Kitamura A, Sasaki T (2003) Rabring7, a novel Rab7 target protein with a RING finger motif. Mol Biol Cell 14: 3741-3752.

9. Miyakawa K, Ryo A, Murakami T, Ohba K, Yamaoka S, et al. (2009) BCA2/ Rabring7 promotes tetherin-dependent HIV-1 restriction. PLoS Pathog 5: e1000700.

10. Kona FR, Stark K, Bisoski L, Buac D, Cui Q, et al. (2012) Transcriptional activation of breast cancer-associated gene 2 by estrogen receptor. Breast Cancer Res Treat 135: 495-503.

*Corresponding author: Q Ping Dou, Barbara Ann Karmanos Cancer Institute Departments of Oncology, Pharmacology and Pathology, School of Medicine Wayne State University, Detroit, MI 48201-2013, USA, Tel: 313-576-8301; Fax: 313-576-8307; E-mail: doup@karmanos.org

Received November 26, 2012; Accepted November 27, 2012; Published November 29, 2012

Citation: Kona FR, Dou QP (2012) Targeting Breast Cancer Associated Gene 2 (bca2), a Novel Ubiquitin e3 Ligase for Breast Cancer Treatment. Clin Exp Pharmacol 2:e119. doi:10.4172/2161-1459.1000e119

Copyright: $\odot 2012$ Kona FR, et al. This is an open-access article distributed under the terms of the Creative Commons Attribution License, which permits unrestricted use, distribution, and reproduction in any medium, provided the original author and source are credited. 
Citation: Kona FR, Dou QP (2012) Targeting Breast Cancer Associated Gene 2 (bca2), a Novel Ubiquitin e3 Ligase for Breast Cancer Treatment. Clin Exp Pharmacol 2:e119. doi:10.4172/2161-1459.1000e119

11. Ciechanover A, Orian A, Schwartz AL (2000) Ubiquitin-mediated proteolysis: biological regulation via destruction. Bioessays 22: 442-451.

12. Bueso-Ramos CE, Manshouri T, Haidar MA, Yang Y, McCown P, et al. (1996)
Abnormal expression of MDM-2 in breast carcinomas. Breast Cancer Res Treat 37: 179-188.

13. Chen A, Kleiman FE, Manley JL, Ouchi T, Pan ZQ (2002) Autoubiquitination of the BRCA1*BARD1 RING ubiquitin ligase. J Biol Chem 277: 22085-22092. 